\title{
SUCESSÃO EM EMPRESAS FAMILIARES E SEUS IMPACTOS NA ESTRATÉGIA EMPRESARIAL: ESTUDOS DE CASO EM EMPRESAS DO SETOR DE FABRICANTES DE PRODUTOS MÉDICOS
}

\section{SUCCESSION IN FAMILY BUSINESS AND ITS IMPACT ON BUSINESS STRATEGY: CASE STUDIES IN CORPORATE SECTOR OF MANUFACTURERS OF MEDICAL PRODUCTS}

\section{Silvia Novaes Zilber}

Doutora em Administração pela Faculdade de Economia, Administração e Contabilidade FEA/USP

Professora do Programa de Mestrado e Doutorado em Administração da Universidade Nove de Julho - UNINOVE

E-mail: silviazilber@uninove.br (Brasil)

\section{Emerson Antonio Maccari \\ Doutor em Administração pela Faculdade de Economia, Administração e Contabilidade - FEA/USP Professor do Programa de Mestrado e Doutorado em Administração da Universidade Nove de Julho - UNINOVE \\ E-mail: maccari@uninove.br (Brasil)}

\section{José Vicente Carneiro Filho}

Mestre em Administração pela Universidade Nove de Julho - UNINOVE

E-mail: jve.filho@uol.com.br (Brasil)

\section{Jouliana Jordan Nohara}

Doutora em Administração de Empresas pela Fundação Getulio Vargas - EAESP/FGV- SP

Professora e Pesquisadora do Programa de Mestrado e Doutorado de Administração (PMDA) da

Universidade Nove de Julho - UNINOVE

E-mail:j.nohara@uol.com.br (Brasil) 
Sucessão em Empresas Familiares e seus Impactos na Estratégia Empresarial: Estudos de Caso em Empresas do Setor de Fabricantes de Produtos Médicos

\section{SUCESSÃO EM EMPRESAS FAMILIARES E SEUS IMPACTOS NA ESTRATÉGIA EMPRESARIAL: ESTUDOS DE CASO EM EMPRESAS DO SETOR DE FABRICANTES DE PRODUTOS MÉDICOS}

\section{RESUMO}

Em um mercado de alta competitividade, as exigências de novos posicionamentos mercadológicos, redefinições de objetivos e concepções inovadoras de administração empresarial, se fazem cada vez mais prementes levando as empresas a definirem estratégias competitivas que garantam sua sobrevivência a longo prazo. Uma ocorrência na vida empresarial que pode afetar os rumos da estratégia nas empresas, particularmente nas caracterizadas como familiares, é o processo sucessório, e, as conseqüências que podem advir desse processo necessitam de uma gestão adaptável aos momentos de mudança. Nesse sentido, o objetivo desse trabalho é esclarecer como o processo sucessório ocorre nas pequenas e médias empresas caracterizadas como empresas familiares. Para isso foram estudadas três empresas de um mesmo setor da economia, mais especificamente empresas do setor industrial dos fabricantes de produtos médicos e odontológicos, numa pesquisa exploratória utilizando estudos de caso. Os estudos revelaram pontos coincidentes nas três empresas, podendo-se ressaltar a ocorrência da sucessão do fundador sempre a partir do afastamento do mesmo, seja por falecimento ou por motivos de saúde, e, ainda, quando se aborda as questões relativas à falta de um planejamento mais elaborado para o processo sucessório. Alterações mais significativas puderam ser observadas na estrutura organizacional das empresas logo após a ocorrência da sucessão do fundador, com as empresas assumindo uma nova dinâmica a partir desse fato efetivado.

Palavras-chave: Sucessão; Estratégia; Empresa Familiar.

\section{SUCCESSION IN FAMILY BUSINESS AND ITS IMPACT ON BUSINESS STRATEGY: CASE STUDIES IN CORPORATE SECTOR OF MANUFACTURERS OF MEDICAL PRODUCTS}

\section{ABSTRACT}

In a highly competitive market, the demands of new market positioning, redefinition of objectives and innovative concepts of business management making it increasingly prominent leading companies to define their competitive strategies that ensure long-term survival. An occurrence in business life that can affect the course of strategy in companies, particularly characterized as family members, is the succession process, and the consequences that may result from this process require an adaptive management at times of change. Thus, the purpose of this study is to clarify how the succession process occurs in small and medium enterprises characterized as family businesses. To this end we studied three companies in the same sector of the economy, specifically the industrial sector of manufacturers of medical and dental products, using an exploratory method through case studies. Studies revealed coincident points in the three companies, which may be noted the occurrence of succession when the founder was out of business whether by death or for medical reasons, and even when it addresses issues concerning lack of a more elaborate planning for the succession process. Most significant changes were observed in the organizational structure of enterprises in the immediate aftermath of the succession of the founder, with business taking a new momentum from that fact accomplished.

Keywords: Succession; Strategy; Family Business.

Revista Ibero-Americana de Estratégia - RIAE, São Paulo, v. 9, n. 3, p. 88-111, set./dez. 2010. 


\section{INTRODUÇÃO}

O Serviço Brasileiro de Apoio às Micro e Pequenas Empresas (SEBRAE, 2007), em pesquisa realizada, levantou dados que comprovam que as micros, pequenas e médias empresas (MPME's) no Brasil representam cerca de 98\% do total das empresas brasileiras. Gonçalves (2000) e La Rovére (2001) afirmam que uma característica destas empresas é terem sua origem como empreendimentos familiares, revelando então a representatividade que essas empresas têm no contexto sócio-econômico brasileiro. É importante frisar que não se pode restringir o universo das empresas familiares no segmento MPME's, pois dentre os grandes grupos empresariais do Brasil aparecem empresas com a característica de serem familiares, por exemplo, Pão de Açúcar, Votorantin, Gerdau, entre outros. Passos, Bernhoeft, Bernhoeft, Teixeira (2006) indicam que dentre os 300 maiores grupos privados no Brasil, 265 estão sob o comando ou gestão de grupos familiares, e, se ampliado esse enfoque encontrar-se-ão também exemplos de grandes grupos empresariais mundiais, que também apresentam a característica de serem familiares, alguns exemplos do contexto mundial: Du Pont, Firestone e Ferrari.

Uma das principais dificuldades, no Brasil, quando se pesquisa a segmentação das empresas como familiares, está na falta de informações sobre essa classificação, pois não se pode afirmar que toda empresa familiar é de micro, pequeno ou médio porte. Gersick, Lansberg, Davis e Hampton (1997) apontam que aproximadamente 70\% das empresas em todo o mundo pertencem a famílias. Um fato constatado, e que pode ser utilizado como limitador do estudo, mas que também reforça a importância de se estudar este segmento empresarial, é a dificuldade de se encontrar nos principais órgãos do Brasil como, Instituto Brasileiro de Geografia e Estatística (IBGE); Serviço Brasileiro de Apoio às Micro e Pequenas Empresas (SEBRAE), Banco Nacional de Desenvolvimento Econômico e Social (BNDES), ou Banco Central do Brasil (BACEN), pesquisas ou estatísticas fidedignas que indiquem o percentual de empresas existentes no universo brasileiro que se caracterizem como empresas familiares, limitando-se os estudos e pesquisas encontrados, em qualificá-las nos parâmetros de micro, pequena, média e grande empresa.

Num contexto mercadológico, que traz consigo um aumento da competição entre as empresas, em que a globalização da economia, dentre outros fatores, leva à necessidade de obtenção de vantagens competitivas para sobrevivência a longo prazo, um fator que pode vir a afetar a competitividade das MPME's, caracterizadas como familiares é a questão do processo sucessório.

Entende-se processo sucessório como sendo o rito de transferência de poder e/ou de capital entre a geração, que atualmente dirige a empresa, e a que virá a dirigir, este processo é assim caracterizado também por Leone, Silva e Fernandes (1996). 
Sucessão em Empresas Familiares e seus Impactos na Estratégia Empresarial: Estudos de Caso em Empresas do Setor de Fabricantes de Produtos Médicos

Para uma melhor contextualização neste trabalho, micros, pequenas, médias e grandes empresas estarão caracterizadas pela categorização adotada pelo Sebrae que as classifica de acordo com o número de pessoas empregadas, dividindo-as por setores; sendo que no setor da indústria e construção, a microempresa é aquela com até 19 pessoas empregadas, pequena empresa de 20 a 99 pessoas, média empresa de 100 a 499 pessoas e grande empresa aquelas que possuem neste setor mais de 499 pessoas empregadas; já no setor que abrange o comércio e a prestação de serviços, a classificação segue a seguinte distribuição, microempresa aquela que emprega até 09 pessoas, pequena empresa de 10 a 49 pessoas, média empresa de 50 a 99 pessoas e a grande empresa a que emprega acima de 99 pessoas.

Classificações diferentes podem ser obtidas junto a outros órgãos, como por exemplo, o BNDES que as classifica levando em consideração o faturamento bruto anual das empresas.

Para efeito deste trabalho será considerada a classificação do SEBRAE, por parecer ser um número mais facilmente mensurável do que o obter valores reais do faturamento das empresas.

A conceituação de empresa familiar é encontrada em diversos estudos; entre as várias conceituações temos a de Gersick et al. (1997), o qual apresenta um modelo, bastante abordado em vários outros estudos, de três círculos sobrepostos, representando membros da família, proprietários e regras de gerenciamento e as influências que podem advir dessa interação; já Chrisman, Chua e Sharma (2005) apóiam sua definição de empresa familiar em uma escala abordando aspectos ligados ao poder, experiência e cultura.

O processo sucessório na empresa familiar é uma fase a ser estudada para a identificação de fatores que o caracterizam e influenciam, além da identificação de alterações estratégicas a partir do início do mesmo.

Para estudar os aspectos relacionados à gestão da estratégia da empresa familiar, Sharma, Chrisman e Chua (1997) desenvolveram um modelo que contempla diversos aspectos do processo sucesório que podem influenciar o atingimento da estratégia empresarial e impactar seus diversos objetivos; daí a necessidade de se estudar esse momento empresarial pelas conseqüências estratégicas que podem ocorrer a partir daí. Para exemplificar, os autores indicam que em empresas familiares, a família do proprietário provavelmente influirá em cada passo do processo muito mais do que em empresas não familiares onde essas influências não se apresentam de forma tão significativa.

Nesse contexto surge o seguinte problema de pesquisa: a falta de planejamento para o processo sucessório pode levar a uma ação equivocada em um determinado momento da vida empresarial e, dessa maneira, um comprometimento da longevidade empresarial poderá advir com 
este fato. Nesse sentido, o estudo dos fatores que podem afetar o processo sucessório em uma empresa familiar torna-se importante; assim como o estudo das alterações estratégicas que poderão ocorrer na empresa a partir do processo sucessório.

O problema mostrado traz então a seguinte questão de pesquisa:

Como se caracteriza o processo sucessório em empresas familiares de pequeno e médio porte no Brasil?

A questão de pesquisa levantada leva ao objetivo principal desse trabalho, qual seja, identificar quais ações caracterizam a ocorrência do processo sucessório em uma empresa familiar. Este objetivo leva em conta que certos fatores deflagram um processo de sucessão, que pode ser caracterizado como uma mudança no controle da empresa. O processo sucessório pode levar a mudanças na estrutura organizacional e, ainda, mudanças nos recursos que trazem vantagem competitiva para a empresa familiar, gerando assim os objetivos específicos de pesquisa, que visam identificar:

- Quais fatores podem ser desencadeadores do processo sucessório;

- A existência de planejamento para o processo;

- Possíveis critérios para a escolha dos sucessores;

- As alterações na estrutura organizacional, geradas após o processo sucessório;

- Se o processo sucessório acarreta mudanças nos objetivos estratégicos da empresa.

\section{REVISÃO DA LITERATURA}

\subsection{EMPRESAS FAMILIARES}

Donnelley (1967) considera como empresa familiar aquela que tenha estado ligada a uma família pelo menos durante duas gerações e com ligações familiares que exerçam influência sobre as diretrizes empresariais, os interesses e objetivos da família.

Leone et al. (1996) definem que essas empresas devem possuir determinados indicadores para serem caracterizadas como familiares, entre eles, o seu início deve ter participação de um membro da família, os familiares devem ser presentes na direção e possuírem um vínculo com a propriedade e, os valores do fundador ou da família devem estar identificados com os da firma e, finalmente na sucessão deve ser observado o fator hereditário. 
Sucessão em Empresas Familiares e seus Impactos na Estratégia Empresarial: Estudos de Caso em Empresas do Setor de Fabricantes de Produtos Médicos

Tanto Coelho (2002), quanto Gallo e Ribeiro (1996) apontam que muitas vezes se confunde empresa familiar com pequena e média empresa, e, que o universo das empresas familiares é muito mais amplo, pois se deve considerar que muitos dos maiores grupos empresariais do mundo também são oriundos de empresas familiares.

Bernhoeft (1996) identifica as seguintes características básicas nas empresas familiares: a existência de uma forte valorização da confiança, independente de vínculos familiares; os laços afetivos apresentam-se extremamente fortes e influenciam os comportamentos, os relacionamentos e decisões da empresa; existe uma real valorização da antiguidade na empresa como atributo que muitas vezes supera a exigência de eficácia e da competência. Bernhoeft et al (2006) apontam que a empresa familiar pode assim ser caracterizada também pelo controle societário exercido por uma ou mais famílias ao longo do tempo.

Chua, Chrisman e Sharma (1999) definem uma empresa familiar como um negócio governado e gerenciado com a intenção de manter e perseguir uma visão de negócios, mantendo o seu controle por membros da mesma família ou um pequeno número de familiares em uma postura que potencialize sua sustentabilidade através de gerações da família.

Um dos modelos mais utilizados na literatura sobre empresas familiares é o de Gersick et al. (1997) em que os autores abordam nos primeiros estudos das empresas familiares como sistemas; nesses primeiros estudos os autores indicavam os problemas típicos que parecem afetar a gestão das empresas familiares, apontando como exemplos o nepotismo e a administração não profissional.

Os mesmos autores, estabeleceram uma distinção entre os subsistemas de propriedade e de gerenciamento, focando dentro do círculo da empresa, pois algumas pessoas neste círculo são proprietárias, mas não estão envolvidas na operação da empresa, enquanto outras são gerentes, mas não controlam ações. Então, os autores sugerem um modelo composto por três círculos, com três subsistemas independentes, em que as pessoas possam se colocar em diversas posições dentro do modelo, procurando dessa maneira ampliar a visibilidade das áreas que são comuns a cada uma das partes que podem compor uma empresa familiar e os diversos interesses de cada uma delas. Neste trabalho a empresa familiar foi caracterizada como a empresa que tenha em seu início a participação de uma ou mais famílias e, que na atual gestão encontrem-se ainda pessoas pertencentes à(s) família(s) fundadora(s). 


\subsection{PROCESSO SUCESSÓRIO}

O processo sucessório pode ser considerado como um fato inevitável e que ocorrerá ao longo da existência da empresa familiar. Davis e Harveston (1998) apontam que apesar dessa inevitabilidade o assunto processo sucessório, costuma ser considerado como um tabu nas discussões das famílias proprietárias desses negócios, nem sempre encarando este processo com a real representatividade para a sobrevivência da empresa, adiando uma discussão sobre o planejamento desse assunto até que ocorra a inevitabilidade da ocorrência, seja por qual motivo for. Dyer e Handler (1994) afirmam ser a sucessão o mais importante assunto que a maioria das empresas familiares deveria enfrentar e, ainda, Gorgati (2000) aponta que as estatísticas sobre a mortalidade em empresas familiares reforçando a suspeita de que ambos os processos, sucessão e sobrevivência, estão intimamente ligados e são interdependentes.

Como este trabalho busca identificar os principais impactos do processo sucessório na empresa familiar e sua sustentabilidade, é importante ressaltar que a falta de preparação para este processo poderá causar sérios problemas na gestão da empresa familiar, reforçam esta afirmação Gersick et al. (1997) e Oliveira (2006a) indicando que 70\% das empresas familiares encerram suas atividades com a morte de seu fundador e, que dos $30 \%$ que sobrevivem à segunda geração, somente uma minoria perdura até a terceira geração, e apontam as principais causas da morte das empresas familiares: um primeiro aspecto abordado pelos autores está na concentração, muito pela tradição, em um determinado produto ou serviço, do qual não conseguem sair, mesmo quando o ciclo de vida deste produto ou serviço apresenta uma tendência de declínio; um segundo fator apontado é a falta de um planejamento estratégico estruturado e, finalmente, e considerado muito significativo pelos autores, as brigas pela sucessão do fundador da empresa familiar.

O processo sucessório apresenta-se nem sempre por critérios totalmente objetivos, e, quase sempre é entremeado por conflitos gerados no relacionamento entre os membros da família segundo Bortoli Neto e Moreira Junior (2001) e Lodi (1987, 1989).

Um modelo conceitual é apresentado por Sharma, Chrisman, Pablo e Chua (2001), em que se procura retratar algumas determinantes para que o processo de sucessão na empresa familiar possa ter maior possibilidade de sucesso. No modelo apresentado, a questão das relações pessoais dentro do contexto da empresa familiar e as influências que estas relações podem causar na estrutura dela e na condução da estratégia estabelecida, são representadas como indicadores de um processo sucessório satisfatório tanto para a empresa quanto para os membros da família e os outros interessados que orbitam no universo da empresa familiar

Revista Ibero-Americana de Estratégia - RIAE, São Paulo, v. 9, n. 3, p. 88-111, set./dez. 2010. 
Sucessão em Empresas Familiares e seus Impactos na Estratégia Empresarial: Estudos de Caso em Empresas do Setor de Fabricantes de Produtos Médicos

\subsection{ESTRATÉGIA E SUCESSÃO}

Estratégia está naturalmente ligada aos planos da alta administração para conquistar resultados consistentes com a missão e os objetivos gerais da organização, este ponto é ressaltado por Wright, Kroll e Parnell (2000), que acrescentam ainda três pontos indicadores de vantagens para a organização, quando uma estratégia é claramente definida, cita que a formulação da estratégia é um fato ligado à criação efetiva da mesma, um segundo ponto é a implementação da estratégia na qual estará definida na prática e, finalmente o controle estratégico que consiste na monitoração e modificação, se necessário, da estratégia desde a sua implementação.

As mudanças estratégicas podem sofrer resistências originadas na cultura empresarial, e, mais especificamente no caso da empresa familiar a cultura da família pode ser um fator importante nesse processo. Este fato apontado por Mintzberg, Ahlstrand e Lampel (2000) indicada que as ligações existentes entre os conceitos de cultura e de estratégia nas empresas têm significância na manutenção da estratégia inicial.

Dentre as principais conceituações acerca da questão sobre a estratégia empresarial encontra-se em Mintzberg, Lampel, Quinn e Ghoshal (2006) citando que, tecnicamente, falar sobre estratégia é abordar mudança e não continuidade; os autores também informam que estratégia está relacionada à imposição de padrões estruturados de comportamento em uma organização e, que administrar estratégia freqüentemente é administrar mudança, reconhecer quando uma mudança de curso é de natureza estratégica, reconhecer quando a mudança de curso é possível, desejável e necessária e, então agir. Os diversos momentos da empresa familiar com as alterações na estratégia podem caracterizar os diversos estados da empresa, e, segundo Mintzberg et al. (2000) esses estados são seqüenciados ao longo do tempo da vida empresarial e definem-se como estágios, períodos e ciclos de vida organizacionais. Ainda os mesmos autores apontam como chave para a administração estratégica, a sustentabilidade da estabilidade ou, no mínimo, mudanças estratégicas adaptáveis a maior parte do tempo. Citam, ainda, que esteja também em reconhecer como periódica a necessidade de transformação, e ser capaz de gerenciar esses processos em que podem ocorrer rupturas, sem que ocorra a destruição da organização; neste aspecto pode se inserir o processo sucessório.

Na questão relacionada à estratégia não se apresentam diferenças substanciais entre as empresas familiares e as não familiares; sendo fundamental para a longevidade empresarial a estratégia definida de maneira correta e as alterações quando o mercado assim exige; essas semelhanças e diferenças são reforçadas por Sharma et al. (1997), quando indicam que a estratégia 
básica, tanto em um tipo quanto no outro tipo de empresa, é semelhante na sua formulação, implementação e controle, quando em um contexto que aborde os objetivos de negócios; citam, ainda, os mesmos autores que as diferenças podem existir quando se observa essas empresas em um contexto abordando objetivos específicos, como por exemplo, a forma de implementar a estratégia, quais são os participantes do processo e quais influências podem ser geradas pela cultura organizacional.

Em um modelo construído por Sharma et al. (1997) são apresentados vértices com fatores que gravitam em torno da gestão estratégica em uma empresa familiar. Alguns desses aspectos podem ser destacados por apresentarem envolvimento da família, e, estes apontamentos nos remetem ao modelo VRIO apresentado por Barney e Hesterly (2007), pois também esses autores indicam que este envolvimento pode interferir na gestão da estratégia empresarial no caso das empresas familiares, e, podem ou não gerar uma vantagem competitiva se adequadamente entendido, e, utilizado.

\subsection{ESTRUTURA ORGANIZACIONAL}

Alterações podem ocorrer na estrutura organizacional, em função das variáveis intervenientes do mercado, também do início de um processo sucessório e, ainda, das possíveis mudanças na gestão estratégica.

Mintzberg (2003) indica que a estrutura organizacional da pequena e média empresa pode ser analisada sob a ótica da organização de estrutura simples, na maioria dos casos; e, poderá ser esta a estrutura encontrada no início da empresa familiar, tendo em vista que o autor apresenta que a estrutura simples tende a ser um ambiente ao mesmo tempo, simples e dinâmico. O autor considera um ambiente simples como aquele compreendido por uma pessoa e, que apresenta a tomada de decisões totalmente centralizada por esse indivíduo. Considera também o autor ser a estrutura simples a mais comum de ser encontrada em organizações novas e/ou pequenas, apresentando-se o estágio de desenvolvimento, como ponto importante para a mudança dessa configuração.

\section{METODOLOGIA}

O estudo abordado teve as características de uma pesquisa exploratória. Parece razoável ser exploratório o presente trabalho, tendo em vista que poucos estudos foram encontrados sobre as empresas familiares no Brasil, assim, segundo Selltiz, Jahode, Deutsch e Cook (1975) é indicado 
Sucessão em Empresas Familiares e seus Impactos na Estratégia Empresarial: Estudos de Caso em Empresas do Setor de Fabricantes de Produtos Médicos

que um estudo exploratório tem o objetivo principal de familiarizar-se com o fenômeno ou ainda, conseguir nova compreensão para o mesmo, principalmente onde o conhecimento é ainda reduzido. Para Gil (1991), a pesquisa exploratória visa proporcionar maior familiaridade com o problema com vistas a torná-lo explícito; envolve ainda um levantamento bibliográfico; entrevistas com pessoas que tiveram experiências práticas com o problema pesquisado; e, ainda, análise de exemplos que estimulem a compreensão. Diferenciar a conceituação entre utilizar-se um estudo de caso único ou um estudo de casos múltiplos, é importante para a correta utilização do método; para diferenciá-los Yin (2005) cita que quando da utilização do estudo de caso único a justificativa está na apresentação de um caso crítico para se testar diretamente determinada teoria; esta não é a situação que se apresenta neste trabalho, pois não se identifica uma determinada empresa como o único exemplo a confirmar o modelo de estudo proposto.

\subsection{COLETA DE DADOS}

Foi utilizada neste trabalho a coleta de dados a partir de informações obtidas diretamente com as empresas foco deste estudo, buscando-se identificar na amostra a característica fundamental para que sejam empresas familiares, assim conceituadas conforme definido na revisão da litaratura empresa familiar caracterizada como a empresa que tenha em seu início a participação de uma ou mais famílias e, que na atual gestão encontrem-se ainda pessoas pertencentes à(s) família(s) fundadora(s). Nesse trabalho os dados primários foram obtidos pela coleta junto aos dirigentes das empresas e demais envolvidos no processo sucessório, através de entrevistas orientadas por um questionário semi-estruturado; como dados secundários foram utilizados relatórios que puderam ser disponibilizados pelas empresas, e, que trouxeram as informações necessárias para se comprovar as alterações que possam ter ocorrido tanto na estrutura organizacional, quanto nos objetivos e estratégia, por força do processo sucessório e desta maneira pode-se aumentar a confiabilidade da pesquisa, conforme definido por Yin (2005).

Para a escolha das empresas pesquisadas, adotou-se como critério buscar empresas de um mesmo setor econômico e, com isto identificar possíveis fatores e características que sejam comuns ao processo sucessório no setor especifico de atuação das empresas.

Revista Ibero-Americana de Estratégia - RIAE, São Paulo, v. 9, n. 3, p. 88-111, set./dez. 2010. 


\subsection{MODELO DE PESQUISA}

Segundo Eisenhardt (1989) o arcabouço conceitual ou modelo de pesquisa serve para elaborar e auxiliar na especificação dos constructos e, ainda, tecer as relações entre eles. Ainda Eisenhardt (1989) define que esses contructos não necessariamente farão parte do resultado da pesquisa, mas fundamentalmente servirão para manter o foco na questão de pesquisa. Os constructos utilizados neste trabalho estavam focados nos seguintes aspectos, considerando-se pequenas e médias empresas familiares:

- A estrutura organizacional, no seu início de operação e as possíveis alterações ocorridas causadas pela sucessão ou por seu crescimento, observando-se as conceituações sobre estrutura organizacional nas empresas familiares de Gonçalves (2000) e Oliveira (2006a);

- Nas alterações que possam ter ocorrido nos objetivos estratégicos iniciais da empresa e as possíveis conseqüências na competitividade dessas empresas pós-alterações; será considerada a conceituação de Chandler Junior (1962), e, ainda, se estas alterações ocorreram na visão de custos e diferenciação propostas por Porter (2004);

- A influência que pode ser gerada pela participação dos membros da família na gestão da empresa e diretamente no processo sucessório; e, os possíveis critérios na escolha dos sucessores; além da observação se existe a intenção de manter-se na família o comando da empresa ou profissionalizar a gestão.

- As alterações ocorridas nos recursos estratégicos que possam ter ocorrido como conseqüência das mudanças na gestão da empresa em função da sucessão familiar, observando-se a conceituação proposta por Barney e Hesterly (2007).

A partir das considerações acima, elaborou-se um modelo de pesquisa, conforme Figura 1: 
Sucessão em Empresas Familiares e seus Impactos na Estratégia Empresarial: Estudos de Caso em Empresas do Setor de Fabricantes de Produtos Médicos

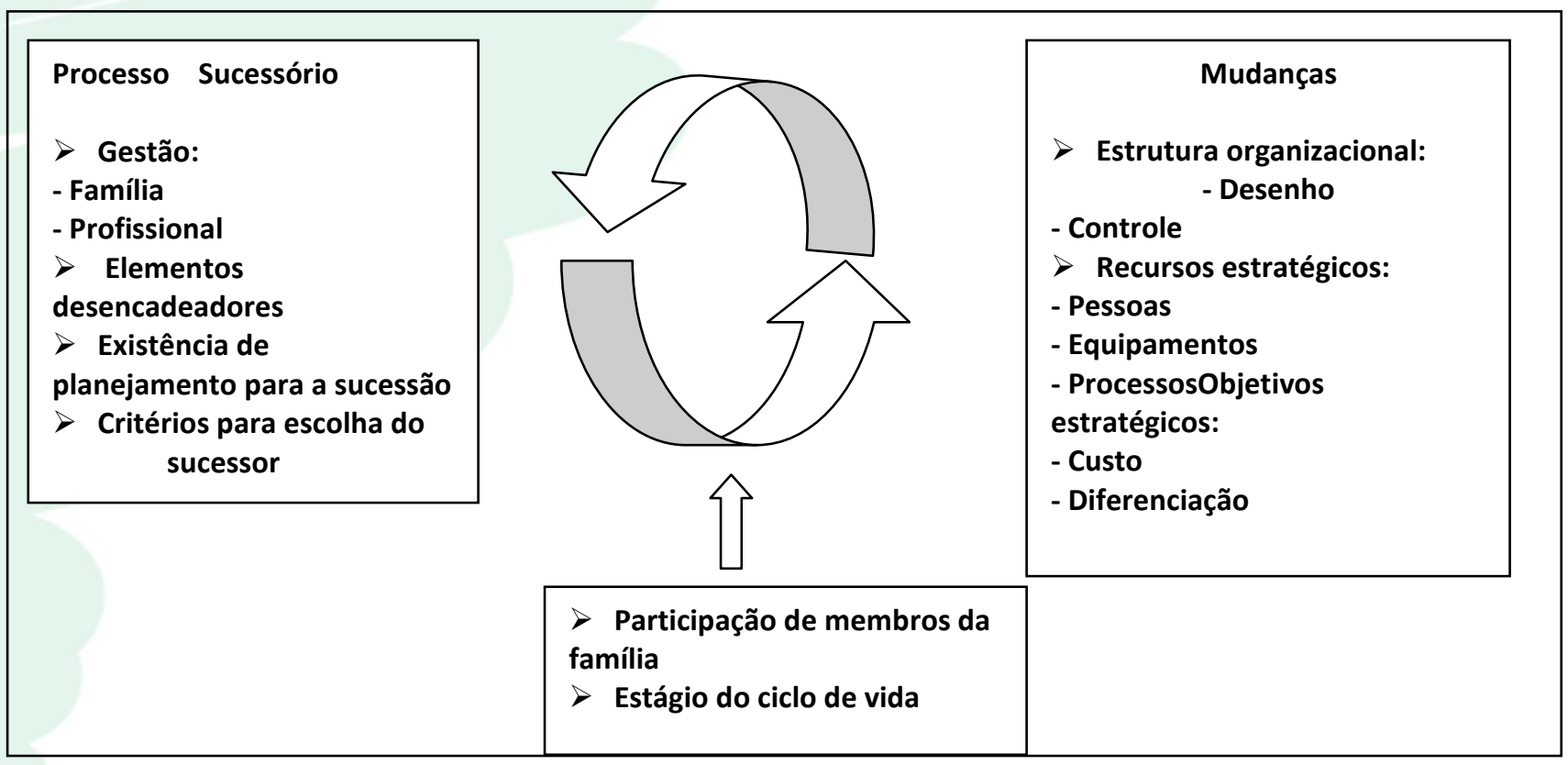

Fonte: Elaborado pelos autores.

Definiu-se nesse trabalho, a partir do modelo proposto, a unidade de análise como sendo a empresa familiar e seu processo sucessório.

A correta gestão deste processo é um ponto relevante, pois a manutençao da gestão da empresa na família ou de cisão por profissionalizar a gestão será uma decisão que poderá ter implicações na sustentabilidade do negócio, necessitando existir um planejamento adequado para esse momento. Essa afirmativa é encontrada em Hitt, Ireland e Hoskisson (2002), no qual os autores indicam que ter um planejamento para a gestão do processo sucessório pode ser considerado um fato crucial e, que o papel do fundador destaca-se na condução deste processo, pois a escolha do sucessor pode sofrer a influência dos interesses da família. Oliveira (2006a) aponta que essa postura na condução será fundamental para a sustentabilidade da empresa.

Os fatores que desencadeiem o processo sucessório podem ser considerados relevantes pela possibilidade de ocorrerem sem que se tenha construído um planejamento adequado para passar pelo processo, fato este apontado por Davis e Harveston (1998). As mudanças que podem advir com o processo sucessório podem ter implicações na estrutura organizacional, pois alterações na organização poderão também ocorrer com a mudança da gestão da empresa, alterando a estrutura inicial que na maioria das pequenas e médias empresas, no seu início de operações, apresenta-se de maneira mais simplificada, este posicionamento é conceituado por Mintzberg (2003).

Nos recursos estratégicos da empresa mudanças também podem ocorrer por força do crescimento da empresa e este crescimento poderá ocorrer concomitantemente ao processo 
sucessório, e alterações nestes recursos podem impactar os objetivos estratégicos da empresa e poderão criar ou manter vantagens competitivas, conforme apontado por Barney e Hesterly (2007).

Os objetivos estratégicos definidos pelo fundador no início da empresa podem, também, sofrer alterações no decorrer do ciclo de vida da empresa, pois podem evoluir de uma gestão totalmente informal, quando da criação e nos primeiros anos da empresa, para a necessidade de uma gestão mais profissionalizada como o crescimento da empresa, este ponto é citado por Sharma et al. (1997).

Para efeito deste trabalho, os fatores intervenientes Participação de membros da família e Estágio do ciclo de vida não serão abordados, apesar de comporem o modelo de pesquisa apresentado.

\subsection{SELEÇÃO DOS CASOS ESTUDADOS}

Os casos utilizados nesse trabalho foram escolhidos de maneira intencional. Conforme Selltiz et al. (1975) indicam, pode-se utilizar dessa técnica para escolher dados que permitam agrupar uma população com características apropriadas para se buscar os objetivos do estudo.

Foram pesquisadas empresas de um mesmo setor da economia para que os resultados possam ser comparados dentro de características mais comuns ao tipo de empresa estudada. A pesquisa se deu em empresas da área de produtos médicos e odontológicos, e, segundo a Associação Brasileira da Indústria de Artigos e Equipamentos Médicos, Odontológicos, Hospitalares e de Laboratórios (ABIMO), fundada em 1962, o setor congrega 319 empresas dos setores de implantes e material de consumo médico-hospitalar, setor de equipamentos médicohospitalares, odontologia, radiologia e diagnóstico por imagem e ainda o setor de laboratórios.

Para a escolha das três empresas pesquisadas adotou-se o critério de enquadramento feito pelo SEBRAE para classificá-las pelo mesmo porte, ou seja, aquele no qual as empresas que possuem um quantitativo de empregados de 50 a 90 empregados podem ser enquadradas como médias empresas, e esse segmento engloba $73 \%$ das empresas do setor, fator relevante para a pesquisa. Outro dado a ser observado está no fato destas estarem no mínimo na segunda geração de familiares na gestão, pois, deste modo, o foco principal deste estudo, o processo sucessório, poderia ser melhor observado. Duas delas estão na segunda geração e uma está na quarta geração, porém as três empresas estão em um momento empresarial de definição da próxima sucessão e da seqüência da família no comando da empresa.

Revista Ibero-Americana de Estratégia - RIAE, São Paulo, v. 9, n. 3, p. 88-111, set./dez. 2010. 
Sucessão em Empresas Familiares e seus Impactos na Estratégia Empresarial: Estudos de Caso em Empresas do Setor de Fabricantes de Produtos Médicos

\section{APRESENTAÇÃO DOS RESULTADOS}

Nesse ítem são apresentadas as empresas que foram estudadas e os principais resultados obtidos nas pesquisas. Como uma das empresas solicitou que não fosse identificada no trabalho, optou-se por manter sem identificação as três empresas, denominando-as no trabalho como Empresa A, Empresa B e Empresa C.

\subsection{PLANEJAMENTO PARA A SUCESSÃO}

Em relação ao planejamento para o processo sucessório, constatou-se nas três empresas que não houve planejamento formal, e em todas as fases foi constatado que o processo de sucessão ocorreu de maneira não previsível, pois os fatos geradores referem-se diretamente às situações ligadas à saúde física dos fundadores. O evento sucessão ocorreu, sem que o assunto tivesse sido discutido abertamente com os filhos. Mais especificamente na empresa C, apesar dos diversos momentos de sucessão pelo qual já passou a empresa, esse planejamento continua não existindo, sendo a posição da atual diretoria procurar a profissionalização de maneira gradual do comando da empresa ou mesmo vender a empresa totalmente. Na empresa B existe, na atualidade, um planejamento claro dos atuais dirigentes para que ocorra o afastamento dos membros da família de forma profissional, permanecendo os membros como conselheiros e passando todas as principais funções de comando para profissionais contratados no mercado. Quanto ao primeiro processo de sucessão poder-se-ia também inferir que quando o fundador trouxe para trabalhar com ele as filhas e procurou ensinar todas as atividades da empresa, mesmo não deixando claro essa questão da sucessão e, mais tarde com a manifesta opinião do fundador que com o nascimento de um filho poderia estar surgindo o seu sucessor, de uma forma meio empírica ele estava planejando a sua sucessão, mesmo não tendo discutido este fato com a família ou mesmo não existindo um projeto formal de sucessão. A empresa A não tem ainda definido se o caminho a ser seguido será o da profissionalização total, podendo haver a opção por um processo de profissionalização parcial da empresa, mantendo-se na família os principais cargos estratégicos de gestão da empresa, preferencialmente no conselho de administração, buscando no mercado pessoas qualificadas para os cargos com exigências mais técnicas. É também definição da atual gestão, que a primeira opção passe por se aproveitar empregados que já estejam na empresa e conheçam os processos administrativos e produtivos.

Revista Ibero-Americana de Estratégia - RIAE, São Paulo, v. 9, n. 3, p. 88-111, set./dez. 2010. 


\subsection{CRITÉRIOS PARA A ESCOLHA DE SUCESSORES}

Na empresa A, os sucessores na gestão do fundador foram escolhidos pelo próprio a partir de critérios subjetivos, dentro do seu conhecimento do que era operar uma empresa e fazê-la crescer, definindo os sucessores entre os filhos e direcionando-os para as áreas que ele considerava mais adequadas a cada um deles. De maneira muito parecida o mesmo aconteceu na empresa B, pois o fundador também direcionou os filhos para áreas de acordo com conceitos que ele próprio definiu; um ponto a se destacar é que segundo os entrevistados quando do nascimento do terceiro filho, um homem, ele deu a entender a todos que finalmente tinha nascido o seu sucessor na empresa. Atualmente os gestores atuam com a clara definição de que não haverá a terceira geração assumindo a empresa, pois é entendimento da atual gestão, composta pelo filho e as duas filhas, profissionalizar a gestão, mantendo-se afastados como conselheiros da empresa.

Na empresa C, apesar de já estar na quarta geração, desde o primeiro processo sucessório a escolha dos sucessores se deu diretamente por aqueles que estavam comandando a empresa e a escolha sempre ocorreu de maneira que o antecessor escolheu o próprio sucessor ao integrá-lo à empresa em determinado momento, sem que houvesse qualquer processo mais elaborado para a escolha do sucessor, e, segundo posição dos atuais administradores não há qualquer definição para a escolha de sucessores e, esta escolha passará primeiramente pela opção de se manter a empresa na família ou não.

A fim de oferecer melhor visualização dos principais resultados obtidos pela pesquisa de forma resumida, foi elaborado o Quadro 1, a partir dos objetivos específicos propostos neste trabalho:

\begin{tabular}{|c|c|c|c|}
\hline & EMPRESA A & EMPRESA B & EMPRESA C \\
\hline $\begin{array}{l}\text { Fato } \\
\text { desencadeador } \\
\text { da sucessão }\end{array}$ & $\begin{array}{l}\text { Afastamento do fundador por } \\
\text { motivos de saúde }\end{array}$ & $\begin{array}{l}\text { Afastamento do fundador por } \\
\text { falecimento }\end{array}$ & $\begin{array}{l}\text { Falecimento nas } 3 \\
\text { sucessões ocorridas. }\end{array}$ \\
\hline $\begin{array}{l}\text { Principais } \\
\text { decisões } \\
\text { durante o } \\
\text { processo }\end{array}$ & $\begin{array}{l}\text { Os filhos foram direcionados } \\
\text { para áreas definidas pelo } \\
\text { fundador. } \\
\text { Filho } 1>\text { Produção } \\
\text { Filho } 2>\text { Producão } \\
\text { Filho } 3>\text { Administração }\end{array}$ & $\begin{array}{l}\text { Os filhos foram direcionados para } \\
\text { áreas definidas pelo fundador, } \\
\text { após a volta da filha mais velha. } \\
\text { Filha } 1>\text { Vendas } \\
\text { Filha } 2 \text { > Administração } \\
\text { Filho } 3 \text { > Produção }\end{array}$ & $\begin{array}{l}\text { Poucas decisões foram } \\
\text { tomadas, pois os processos } \\
\text { ocorreram sem qualquer } \\
\text { direcionamento de área de } \\
\text { atuação para os sucessores, } \\
\text { ficando direto na gestão. } \\
\text { Quadro 1 - Continua }\end{array}$ \\
\hline
\end{tabular}

Revista Ibero-Americana de Estratégia - RIAE, São Paulo, v. 9, n. 3, p. 88-111, set./dez. 2010. 
Sucessão em Empresas Familiares e seus Impactos na Estratégia Empresarial: Estudos de Caso em Empresas do Setor de Fabricantes de Produtos Médicos

Quadro 1 - Continuação

\begin{tabular}{|c|c|c|c|}
\hline $\begin{array}{l}\text { Existência de } \\
\text { planejamento } \\
\text { para a sucessão. }\end{array}$ & $\begin{array}{l}\text { Primeira geração: inexistência } \\
\text { de planejamento formal. } \\
\text { Segunda geração: inexistência } \\
\text { de planejamento formal. }\end{array}$ & $\begin{array}{l}\text { Primeira geração: inexistência de } \\
\text { planejamento formal. } \\
\text { Segunda geração: existe planos } \\
\text { para a sucessão. }\end{array}$ & $\begin{array}{l}\text { Não foi encontrado } \\
\text { qualquer planejamento para } \\
\text { a sucessão nas três } \\
\text { ocorrências já havidas. }\end{array}$ \\
\hline $\begin{array}{l}\text { Critério para } \\
\text { escolha dos } \\
\text { sucessores }\end{array}$ & $\begin{array}{l}\text { Primeira geração > ser filho e } \\
\text { trabalhar na empresa. } \\
\text { Segunda geração > ser da } \\
\text { família e trabalhar na empresa } \\
\text { com profissionalização das } \\
\text { áreas técnicas. }\end{array}$ & $\begin{array}{l}\text { Primeira geração > ser filho e } \\
\text { trabalhar na empresa. } \\
\text { Segunda geração > } \\
\text { Profissionalizar a gestão, família } \\
\text { no conselho de administração. }\end{array}$ & $\begin{array}{l}\text { Primeira geração > ser da } \\
\text { família. } \\
\text { Segunda geração > ser da } \\
\text { família. } \\
\text { Terceira geração > ser da } \\
\text { família } \\
\text { Quarta geração > ser da } \\
\text { família/ profissionalizar ou } \\
\text { vender a empresa. }\end{array}$ \\
\hline $\begin{array}{l}\text { Estrutura } \\
\text { organizacional }\end{array}$ & $\begin{array}{l}\text { Início > Informal, } \\
\text { centralizada, fundador era } \\
\text { único chefe. } \\
\text { Atual > Formal, organograma } \\
\text { com cargos e funções } \\
\text { definidos, autonomia de } \\
\text { decisões. }\end{array}$ & $\begin{array}{l}\text { Início > Informal, centralizada, } \\
\text { fundador era o único chefe. } \\
\text { Atual > Formal, organograma com } \\
\text { cargos e funções definidos, } \\
\text { autonomia de decisões. }\end{array}$ & $\begin{array}{l}\text { Início > Informal, } \\
\text { centralizada, fundador era o } \\
\text { único chefe. } \\
\text { Atual > Formal, } \\
\text { organograma simplificado, } \\
\text { funções definidas nos } \\
\text { cargos mais diretamente } \\
\text { ligadas à diretoria. }\end{array}$ \\
\hline $\begin{array}{l}\text { Objetivos } \\
\text { estratégicos }\end{array}$ & $\begin{array}{l}\text { Início > Mercado nacional } \\
\text { (cidade de São Paulo), } \\
\text { produtos para mecanoterapia, } \\
\text { qualidade dos produtos, casa } \\
\text { para os filhos. } \\
\text { Atual > Mercados nacional e } \\
\text { internacional, qualidade de } \\
\text { produtos, mecanoterapia, } \\
\text { hidroterapia e eletroterapia. }\end{array}$ & $\begin{array}{l}\text { Início > Mercado Nacional (cidade } \\
\text { de São Paulo), instrumentos } \\
\text { cirúrgicos de maneira artesanal, } \\
\text { qualidade dos produtos, } \\
\text { subsistência da família. } \\
\text { Atual> Mercados nacional e } \\
\text { internacional, qualidade dos } \\
\text { produtos, ampliação dos produtos } \\
\text { acompanhando a evolução da área } \\
\text { de cirurgias médicas. }\end{array}$ & $\begin{array}{l}\text { Início > Mercado nacional, } \\
\text { artigos domésticos e } \\
\text { acessórios para a área } \\
\text { hospitalar. } \\
\text { Atual > Mercados nacional } \\
\text { e internacional, artigos } \\
\text { acessórios para a área } \\
\text { médico-hospitalar e } \\
\text { veterinária. }\end{array}$ \\
\hline \multicolumn{4}{|r|}{ Quadro 1 - Continua } \\
\hline & & & Quadro 1 - Continuação \\
\hline & $\begin{array}{l}\text { Início > máquinas simples, } \\
\text { controle manual dos clientes, } \\
\text { contratação de pessoal por } \\
\text { indicação, treinamento feito } \\
\text { pelo fundador. }\end{array}$ & $\begin{array}{l}\text { Início > poucas máquinas simples, } \\
\text { controle de clientes por anotações } \\
\text { em papeletas, pessoal contratado } \\
\text { por indicação e treinamento no } \\
\text { serviço. }\end{array}$ & $\begin{array}{l}\text { Início > } 1 \text { motor fazia girar } \\
\text { todos os tornos, produtos } \\
\text { simples para lar e alguns } \\
\text { acessórios hospitalares, } \\
\text { pouco treinamento de } \\
\text { pessoal contratado por } \\
\text { indicação, produtos à base } \\
\text { de latão e niquelados. }\end{array}$ \\
\hline
\end{tabular}




\begin{tabular}{|c|c|c|c|}
\hline $\begin{array}{l}\text { Mudança dos } \\
\text { recursos } \\
\text { estratégicos }\end{array}$ & $\begin{array}{l}\text { Atual > máquinas mais } \\
\text { sofisticadas, área de pesquisa, } \\
\text { laboratório de testes } \\
\text { eletrônicos, contratação de } \\
\text { pessoal por indicação, } \\
\text { treinamento profissional, } \\
\text { sistema ERP para controles, } \\
\text { processos de certificações de } \\
\text { qualidade nacional e } \\
\text { internacional. }\end{array}$ & $\begin{array}{l}\text { Atual > } 46 \text { máquinas, sistema } \\
\text { PROTEUS para gestão, empresas } \\
\text { contratadas para seleção de } \\
\text { pessoal, certificações de qualidade } \\
\text { nacional e internacional. }\end{array}$ & $\begin{array}{l}\text { Atual > grandes máquinas, } \\
\text { produtos à base de aço } \\
\text { inox, alumínio e plástico, } \\
\text { pessoal contratado com } \\
\text { experiência. }\end{array}$ \\
\hline $\begin{array}{l}\text { Mudança nas } \\
\text { vantagens } \\
\text { competitivas }\end{array}$ & $\begin{array}{l}\text { Início > nome da família, } \\
\text { qualidade dos produtos como } \\
\text { diferencial, relacionamento } \\
\text { direto com os clientes. } \\
\text { Atual > nome da família, } \\
\text { qualidade dos produtos como } \\
\text { diferencial, relacionamento } \\
\text { direto com os clientes, } \\
\text { internacionalização da marca } \\
\text { através das certificações de } \\
\text { qualidade, incremento de } \\
\text { tecnologia gerando maior } \\
\text { valor agregado aos produtos. }\end{array}$ & $\begin{array}{l}\text { Início > qualidade dos produtos } \\
\text { como diferencial, relacionamento } \\
\text { direto com os clientes. } \\
\text { Atual > qualidade dos produtos } \\
\text { como diferencial, relacionamento } \\
\text { com os clientes, } \\
\text { internacionalização dos produtos } \\
\text { através das certificações de } \\
\text { qualidade, produção de novos } \\
\text { equipamentos para atender às } \\
\text { novas demandas de cirurgia. }\end{array}$ & $\begin{array}{l}\text { Início > produtos para } \\
\text { residências e hospitais, } \\
\text { poucos concorrentes. } \\
\text { Atual > produtos com } \\
\text { novos materiais, mas sem } \\
\text { grande variação em relação } \\
\text { aos inicialmente } \\
\text { produzidos. }\end{array}$ \\
\hline
\end{tabular}

Quadro 1- Resumo dos principais dados da pesquisa.

Fonte: Elaborado pelos autores.

Os resultados encontrados nesta pesquisa mostram que, como não existem ações atreladas às rotinas das empresas ligadas diretamente à sucessão, as decisões tomadas no cotidiano das empresas estão mais conectadas às questões operacionais e administrativas, não havendo ações específicas que possam ser consideradas fazendo parte de um processo sucessório planejado de antemão.

Este fato implicou na busca de certificações em processos de qualidade e, com isso, equipamentos foram sendo adquiridos para que a qualidade dos produtos atendesse às exigências dos novos mercados que passaram a ser foco das empresas. Um fato constatado, e que vem sendo mantido pelas atuais gestões, é o princípio da qualidade definido pelos fundadores como fator de diferenciação para a sobrevivência das empresas.

Mudanças nos objetivos e recursos estratégicos ocorreram mais por força do crescimento das empresas e exigências do mercado, do que por força da sucessão, apesar de que com a assunção da segunda geração nas empresas A e B, mudanças mais importantes ocorreram nos recursos, por força do reposionamento da empresa para a conquista de novos mercados

Especificamente em relação aos objetivos estratégicos das empresas estudadas, no início estes objetivos estavam mais direcionados para a conquista de um mercado ainda emergente; a 
Sucessão em Empresas Familiares e seus Impactos na Estratégia Empresarial: Estudos de Caso em Empresas do Setor de Fabricantes de Produtos Médicos

empresa mais antiga, a empresa C, que foi fundada em 1915, tinha, o foco claro de vender seu produto pelo menor preço possível e dessa maneira conquistar clientes; as demais empresas foram fundadas no período a partir de 1950 e se constatou que o principal objetivo era conquistar os clientes a partir de uma estratégia baseada fundamentalmente na qualidade dos produtos, estratégia essa que permanece até a atualidade.

\section{CONSIDERAÇÕES FINAIS}

O planejamento para o processo sucessório praticamente inexiste de maneira estruturada nas empresas pesquisadas, e, por conseguinte, a escolha dos futuros sucessores só ocorre quando a necessidade de sucessão (por afastamento do fundador por morte ou problema de saúde) efetivamente se instala nas empresas.

Como o objetivo geral deste trabalho foi esclarecer como o processo sucessório ocorre nas pequenas e médias empresas caracterizadas como empresas familiares, o que se pode constatar é que o processo sucessório é tratado como algo periférico às empresas, não sendo foco de ações rotineiras das administrações. Outra constatação é que apesar de atualmente as empresas sinalizarem preocupação com a questão da sucessão, não existe instalado qualquer planejamento estruturado para que a condução do processo seja feita ao longo do ciclo de vida da empresa, somente quando o fato for consumado pela sua inevitabilidade é que o assunto sucessão aparece em pauta; essas constatações vêm ao encontro das colocações feitas por Davis e Harveston (1998) no qual a inevitabilidade do processo é apontado como importante fato e, que é tratado de maneira não focada pelas empresas familiares.

Sobre recursos estratégicos, Barney e Hesterly (2007) os definem como: aqueles que podem gerar vantagens competitivas e, ainda, que permite à empresa explorar uma oportunidade ambiental, e, ainda Chrisman et al. (2005) referindo-se à questão do RBV, indicam que quando se aborda o estudo de uma empresa familiar é necessário considerar-se o envolvimento da família também como recurso inimitável. Foi constatada na pesquisa que as empresas sofreram alterações em diversos recursos que podem ser considerados estratégicos, por estarem diretamente ligados à questão da produção e organização da estrutura organizacional. Efetivamente foram adquiridos novos recursos, considerando-se máquinas, equipamentos de informática, sistemas de gestão que foram agregados às empresas e considerados como fundamentais em função do crescimento das mesmas; pode-se, ainda, registrar que durante a gestão do fundador poucas foram as alterações 
sofridas nos recursos iniciais, os controles eram feitos de maneira manual, a produção tinha muito de artesanal, este fato pode ser constatado nas três empresas pesquisadas. Ao considerar-se a questão família como um RBV, constata-se que os fundadores mesmo que de maneira instintiva usaram essa questão da valorização do nome familiar como um recurso a ser agregado e a ser conectado à questão da qualidade dos produtos e, este fato permanece até a atual gestão, podendo ser considerada como uma estratégia de reforço da marca, o uso do nome familiar para se firmar como um referencial no mercado.

Mudanças significativas foram observadas na estrutura organizacional a partir do afastamento do fundador, e este fato foi indicado nas empresas pesquisadas por causa da posição de centralizador das decisões que os fundadores adotaram desde o início da empresa. Pode-se confirmar essa dinâmica a partir do estudo feito por Masurel e Montfort (2006), no qual são indicados alguns tópicos básicos das fases de evolução das empresas em relação à sua organização, diretamente ligadas à posição do fundador ao longo do tempo. Estas alterações ocorreram de maneira mais intensa a partir deste momento, da sucessão, pelas decisões dos sucessores que ao assumirem, definiram novas políticas para a empresa. Constatou-se que a saída do fundador tende a gerar uma divisão de atribuições entre os sucessores, pois nas empresas pesquisadas os fundadores tinham forte tendência centralizadora, e, mesmo na ocorrência dessa divisão, ainda pode ser observada que a opinião do fundador tem peso significativo. As atribuições de autoridade para decisões continuam a ser centralizadas nos membros da família e, ficam mais no aspecto técnico as responsabilidades inerentes a terceiros não pertencentes ao núcleo familiar. Felthan, Felthan e Barnett (2005) consideram que é importante os proprietários trabalharem para reduzir o nível de dependência do negócio da família neles próprios; este posicionamento, porém, não foi observado nas empresas, pois principalmente em relação aos fundadores, em momento algum foi percebida esta intenção.

Desta frma, respondendo a um dos bjetivos da pesquisa, qual seja, levantar quais fatores podem ser desencadeadores do processo sucessório, o que se encontrou na presente pesquisa foi que na sucessão do fundador da empresa, o processo ocorre gerado pelo afastamento do fundador por motivo de doença ou falecimento, sendo as decisões sobre quem serão os sucessores tomadas de maneira direta pelos fundadores a partir de seus conhecimentos e dos objetivos definidos para a empresa que fundou; essa indicação de sucessores por parte do fundador é mais direcionada pelo próprio de maneira intuitiva.

Quanto aos objetivos de se levantar a existência de planejamento para o processo e os possíveis critérios para a escolha dos sucessores, o que se percebeu foi que não existem critérios 
Sucessão em Empresas Familiares e seus Impactos na Estratégia Empresarial: Estudos de Caso em Empresas do Setor de Fabricantes de Produtos Médicos

objetivos pré-estabelecidos para a escolha do sucessor em nenhuma das empresas entrevistadas. Estas decisões não demandam de maneira formal que exista um planejamento para a sucessão, pois no caso das empresas pesquisadas em momento algum foi constatado pelos sucessores qualquer discussão dos fundadores em relação a esse assunto; o que ocorria é que os fundadores direcionavam os filhos para atividades dentro da empresa que poderiam ou não serem mantidas após seu afastamento.

Quanto ao objetivo de identificar quais as alterações na estrutura organizacional geradas após o processo sucessório, observou-se que as alterações na estrutura organizacional são mais significativas a partir da saída do fundador e, por conseqüência, essas alterações podem gerar também mudanças nos recursos estratégicos e objetivos iniciais da empresa.

Estas alterações mostraram que, após a saída do fundador, ocorre uma descentralização mais acentuada nas empresas quanto ao poder de decisão quando aparece a ocorrência de mais de um sucessor, permitindo um maior compartilhamento das tomadas de decisão, levando as empresas a ficarem mais adequadas às exigências do mercado no qual estão inseridas.

Um fator limitante da pesquisa refere-se à utilização do método de estudo de caso, que não permite a generalização para toda a população foco do estudo, neste caso as empresas familiares.

A amostra em relação ao universo das empresas familiares pode ser considerada pequena, mas procurou-se entrevistar nas empresas as pessoas do grupo familiar que ocupam posições de decisão e que podem ter alguma influência no processo sucessório, além de serem sucessores dos últimos gestores.

Como sugestão para estudos futuros tem-se: ampliar a amostra de empresas pesquisadas, estudar a questão relacionada ao porte da empresa, e, se este fato é um fator de diferenciação para a condução do processo sucessório. Outra oportunidade de pesquisas futuras seria verificar se a formação dos fundadores tem algum efeito sobre a questão do planejamento sucessório: fundadores gestores mais profissionais, com nível superior, poderiam estar mais preocupados com a questão sucessória, e seriam mais afeitos ao planejamento do que fundadores que tocaram suas empresas de forma mais informal.

Revista Ibero-Americana de Estratégia - RIAE, São Paulo, v. 9, n. 3, p. 88-111, set./dez. 2010. 


\section{REFERÊNCIAS}

Barney, J. B., \& Hesterly, W. S. (2007). Administração estratégica vantagem competitiva. São Paulo: Pearson Prentice Hall.

Bernhoeft, R. (1996). Como criar, manter e sair de uma sociedade familiar (sem brigar). São Paulo: SENAC.

Bortoli Neto, A., \& Moreira Junior, A. L. (2001). Dificuldades para a realização da sucessão: um estudo em empresas familiares de pequeno porte. Recuperado em 20 de junho, 2007, de http://www.ead.fea.usp.br/Semead/5semead/Adm.\%20Geral/Dificuldades\%20para\%20realizaca o\%20da\%20sucessao.pdf.

Chandler Junior, A. D. (1962). Strategic and structure: chapters in the history of American industrial enterprises. Massachusetts Institute of Technology.

Chua, J. H., Chrisman, J. J., \& Sharma, P. (1999). Defining the family business by behavior. Entrepreneurship: Theory and Practice, 23(4), 19-39.

Chua, J. H., Chrisman, J. J., \& Steier, L. P. (2003). Extending the theoretical horizons of family business research. Entrepreneurship: Theory and Practice, 27(4), 331-338.

Coelho, A. J. (2002). Aspectos críticos numa empresa familiar - estudo de um caso. Recuperado em 20 de junho, 2007, de http://www.ensino.eu/em-artigo03.pdf.

Chrisman, J. J., Chua, J. H., \& Sharma, P. (2005). Trends and directions in the development of a strategic management theory of the family firm. Entrepreneurship: Theory and Practice, 29(5), $555-576$.

Davis, P. S., \& Harveston, P. D. (1999). In the founder's shadow: conflict in the family firm. Family Business Review, 12(4), 311-335.

Davis, P. S., \& Harveston, P. D. (1998). The influence of family business succession process: a multi-generational perspective. Entrepreneurship: Theory and Practice, 22(3), 31-53.

Donnelley, R. G. (1967). A empresa familiar. Revista de Administração de Empresas, 7(23), 161198.

Dyer, W., \& Handler, W. (1994). Entrepreneurship and family business: exploring the connections. Entrepreneurship: Theory and Practice, 19(1), 71-83.

Eisenhardt, K. M. (1989). Building theories from case study research. Academy of Management Review, 14(4), 532-550. 
Sucessão em Empresas Familiares e seus Impactos na Estratégia Empresarial: Estudos de Caso em Empresas do Setor de Fabricantes de Produtos Médicos

Feltham, T. S., Feltham, G., \& Barnett, J. J. (2005). The dependence of family business on a single decision-marker. Journal of Small Business Management, 43(1), 1-15.

Gallo, M. A., \& Ribeiro, V. S. (1996). A gestão das empresas familiares. Lisboa: Almedina.

Gersick, K. E., Lansberg, I., Davis, J.A., \& Hampton, M. M. (1997). Generation to generation: life cycles of family business. New York: Prentice Hall.

Gil, A. C. (1999). Métodos e técnicas de pesquisa social. São Paulo: Atlas.

Gil, A. C. (1991). Como elaborar projetos de pesquisa. São Paulo: Atlas.

Gonçalves, J. S. R. C. (2000). As empresas familiares no Brasil. RAE Light - Revista de Administração de Empresas, 7(1), 7-12.

Gorgati, V. (2000). Os determinantes da estrutura de capital de empresas familiares brasileiras durante os processos sucessórios. Dissertação de Mestrado, Faculdade de Economia, Administração e Contabilidade da Universidade de São Paulo, Universidade de São Paulo, São Paulo.

Handler, W. C. (1991). Key interpersonal relationships of next-generation family members in family firm. Journal of Small Business Management, 29(3), 21-32.

Harris, D., Martinez, J. I., \& Ward, J. L. Is strategy different for the family-owned business? Family Business Review, 7(2), 159-174.

Hitt, M. A., Ireland, R. D., \& Hoskisson, R. E. (2002). Administração estratégica. São Paulo: Thomson Learning.

La Rovere, R. L. (2001). Perspectivas das micro, pequenas e médias empresas no Brasil. Revista de Economia Contemporânea, 5, 1-22.

Lee, J. (2004). The effects of family ownership and management on firm performance. SAM Advanced Management Journal, 69(4), 46-53.

Leone, N. M. C. P. G., Silva, A. B., \& Fernandes, C. B. (1996). Sucessão: como transformar o duelo em dueto. Revista de Administração da Universidade de São Paulo, 31(3), 76-81.

Lodi, J. B. (1989). O fortalecimento da empresa familiar. São Paulo: Pioneira.

Lodi, J. B. (1987). Sucessão e conflito na empresa familiar (3a ed.). São Paulo: Pioneira. 
Masurel, E., \& Montfort, K. V. (2006). Life cycle characteristics of small professional service firms. Journal of Small Business Management, 44(3), 461-473.

Mello, D. N. (1995). A sucessão na empresa familiar. Revista da Economia e Empresa, 2(2), 68-70.

Mintzberg, H. (2003). Criando organizações eficazes: estruturas em cinco configurações (2a ed.) São Paulo: Atlas.

Mintzberg, H., Ahlstrand, B., \& Lampel, J. (2000). Safári de estratégia: um roteiro pela selva do planejamento estratégico (N. Montigelli Junior, Trad.). Porto Alegre: Bookman.

Mintzberg, H., Lampel, J., Quinn, J. B., \& Ghoshal, S. (2006). O processo da estratégia: conceitos, contextos e casos selecionados (4a ed.). Porto Alegre: Bookman.

Mintzberg, H., \& Quinn, J. B. (2001). O processo de estratégia (J. S. Cook, Trad.) (3a ed.). Porto Alegre: Bookman

Oliveira, D. P. R. (2006a). Empresa familiar: como fortalecer o empreendimento e otimizar o processo sucessório (2a ed.). São Paulo: Atlas.

Oliveira, D. P. R. (2006b). Estrutura organizacional: uma abordagem para resultados e competitividade. São Paulo: Atlas.

Passos, E., Bernhoeft, R., Bernhoeft, R., Teixeira, W. (2006). Família, família, negócios à parte: como fortalecer laços e desatar nós na empresa familiar. São Paulo: Gente.

Porter, M. E. (2004). Estratégia competitiva (E. M. P. Braga, Trad.). (2a ed.). Rio de Janeiro: Campus/Elsevier.

Serviço Brasileiro de Apoio às Micro e Pequenas Empresas. (2007). Anuário do trabalho na micro e pequena empresa. Recuperado em 20 de outubro, 2007, de http://www.sebraesp.com.br/principal/conhecendo\%20a\%20mpe/mpes\%20em\%20n\%C3\%BAm eros/.

Serviço Brasileiro de Apoio às Micro e Pequenas Empresas. (2004). Fatores condicionantes da mortalidade e taxa de mortalidade de empresas no Brasil. Recuperado em 20 de julho, 2007, de http://www.sebrae.com.br/br/mortalidade_empresas/index.asp>.

Selltiz, C., Jahode, M., Deutsch, M., \& Cook, S. W. (1975). Métodos de pesquisa nas relações sociais (D. M. Leite, Trad.). São Paulo: EDUSP.

Sharma, P. (2004). An overview of the field of family business studies: current status and directions for the future. Family Business Review, 17(1), 1-36.

http://dx.doi.org/10.1111/j.1741-6248.2004.00001.x 
Sucessão em Empresas Familiares e seus Impactos na Estratégia Empresarial: Estudos de Caso em Empresas do Setor de Fabricantes de Produtos Médicos

Sharma, P., Chrisman, J. J., \& Chua, J. H. (2003). Succession planning as planned behavior: some empirical results. Family Business Review, 16(1), 1-15.

Sharma, P., Chrisman, J. J.., \& Chua, J. H. (1997). Strategic management of the family business: past research and future challenges. Family Business Review, 10(1), 1-36.

Sharma, P., Chrisman, J. J., Pablo, A. L., \& Chua, J. H. (2001). Determinants of initial satisfaction with the succession in family firms: a conceptual model. Entrepreneurship: Theory and Practice, 25(3), 2-33.

Uller, R. (2002). Profissionalização na empresa familiar: o caso da Perdigão Agroindustrial S/A. Dissertação de Mestrado, Centro Tecnológico da Universidade Federal de Santa Catarina, Florianópolis.

Wright, P., Kroll, M. J., \& Parnell, J. A. (2000). Administração estratégica: conceitos (C. A. Rimoli \& L. R. Esteves, Trad.). São Paulo: Atlas.

Yin, R. K. (2006). Estudo de caso: planejamento e métodos (D. Grassi, Trad.) (3a ed.). Porto Alegre: Bookman.

Recebido: 15/07/2010

Aprovado: 25/10/2010

Revista Ibero-Americana de Estratégia - RIAE, São Paulo, v. 9, n. 3, p. 88-111, set./dez. 2010. 